\title{
High Stakes in the Classroom, High Stakes on the Street: The Effects of Community Violence on Students' Standardized Test Performance
}

\author{
Patrick Sharkey, ${ }^{a}$ Amy Ellen Schwartz, ${ }^{a}$ Ingrid Gould Ellen, ${ }^{a}$ Johanna Lacoe ${ }^{b}$ \\ a) New York University; b) University of Southern California
}

\begin{abstract}
This article examines the effect of exposure to violent crime on students' standardized test performance among a sample of students in New York City public schools. To identify the effect of exposure to community violence on children's test scores, we compare students exposed to an incident of violent crime on their own blockface in the week prior to the exam to students exposed in the week after the exam. The results show that such exposure to violent crime reduces performance on English language arts assessments and has no effect on math scores. The effect of exposure to violent crime is most pronounced among African Americans and reduces the passing rates of black students by approximately 3 percentage points.
\end{abstract}

Keywords: community violence; neighborhood effects; academic performance; racial disparities; school settings

Editor(s): Jesper Sørensen, Stephen L. Morgan; Received: October 29, 2013; Accepted: December 20, 2013; Published: May 27, 2014

Citation: Sharkey, Patrick, Amy Ellen Schwartz, Ingrid Gould Ellen, and Johanna Lacoe. 2014. "High stakes in the classroom, high stakes on the street: The effects of community violence on students' standardized test performance." Sociological Science 1: 199-220. D0I: 10.15195/v1.a14

Copyright: (c) 2014 Sharkey et al.. This open-access article has been published and distributed under a Creative Commons Attribution License, which allows unrestricted use, distribution and reproduction, in any form, as long as the original author and source have been credited.

$\prod \mathrm{H}$ HERE is a longstanding debate in the field of education about the degree to which conditions outside of school settings shape academic performance and contribute to the large and persistent gaps between students of different backgrounds. Although this debate has generated a tremendous amount of empirical attention, we argue that progress toward understanding how aspects of the home or neighborhood environment affect educational inequality has been impeded by three limitations in much of the empirical literature: incomplete or underdeveloped theory on the mechanisms and processes by which disadvantage in the home or school setting affects performance in school; imprecise measurement of these mechanisms; and the widespread use of analytic methods that rely on implausible assumptions.

This article is designed to advance this debate by making progress on all three of these fronts while presenting evidence on the role of community violence as a pathway through which inequality outside the school setting makes its way into the school to affect educational inequality. We put forth a conceptual model that links discrete stressors occurring in students' residential environments to impaired performance in school, with consequences that have the potential to alter academic trajectories and exacerbate racial achievement gaps. Focusing on one specific set of stressors, incidents of violent crime, the empirical analysis capitalizes on new data and develops new methods to provide a rigorous test of how exposure to incidents of violent crime affects student standardized test performance.

Specifically, we merge unique data on the precise location and timing of violent crimes in New York City with similarly precise data on the residential location of all New York City elementary and middle-school public school students from 2004 to 2010. We develop an empirical strategy that compares the test scores of students living on blockfaces (street segments bordered by the two closest cross streets) where violent crimes occur just before a standardized test to the scores of otherwise comparable students who live on blockfaces where similar crimes occur just after a test. Under the assumption that the timing of violent crime incidents relative to the timing 
of standardized assessments is exogenous, any differences in test scores should reflect the acute effect of pretest exposure to violent crime.

Results from an array of models indicate that students who live on blockfaces where violent crimes occur just before a standardized test perform significantly worse on English language arts (ELA) assessments than students who live on blockfaces where violent crimes occur just after the exam; there are no effects on math assessments. Impacts on ELA exams are particularly pronounced for black students and for students in elementary school The findings are consistent with research conducted in Chicago showing that exposure to recent local homicides reduces children's performance on assessments of cognitive skills (Sharkey 2010; Sharkey et al., 2012). However, the findings in this study indicate that forms of violence less severe than homicides still affect children's academic performance. More importantly, the effect of local violence is not limited to low-stakes assessments conducted by interviewers within the child's home but extends to high-stakes standardized assessments that are important for children's academic trajectories.

This study provides convincing evidence of one concrete way in which the burdens associated with life in a disadvantaged residential neighborhood are carried into the classroom to affect academic performance. Considering the consequences of standardized test performance for students, teachers, and schools in New York City, the estimated effects of exposure to local violence have important implications for the weight given to standardized assessments as a tool for the evaluation of academic achievement and progress.

\section{Literature and Theory}

\section{Neighborhood Disadvantage, Community Violence, and School Performance}

With few exceptions, the empirical literature demonstrates a strong link between neighborhood disadvantage and various educational outcomes (Ellen and Turner 1997). There is extensive evidence from observational studies that living in a poor or disadvantaged residential environment reduces educational attainment and lowers test scores, with larger effects for children exposed to disadvantaged environments for longer periods of childhood (Harding 2003; Sampson, Sharkey and Raudenbush 2008; Sharkey and Elwert 2011; Wodtke, Harding and Elwert 2011). Evidence from residential mobility programs is less consistent. Research based on the Gautreaux Assisted Housing Program, which began in the 1970s in Chicago, showed that children from low-income families who were assigned residential units in Chicago's suburbs initially had difficulty in their new schools but ultimately were much more likely to graduate and go on to college than families who were assigned to apartments within Chicago's city limits (Rubinowitz and Rosenbaum 2000). The design of the Gautreaux studies has been criticized, however, as it is not clear that families' residential destinations were entirely exogenous (Mendenhall, DeLuca, and Duncan 2006; Votruba and Kling 2009).

Results from the Moving to Opportunity (MTO) experiment, a randomized study conducted in five cities in the mid-1990s, are more difficult to interpret. An initial study that pooled respondents from all five cities found no overall effect of moving to low-poverty neighborhoods on children's test scores (Sanbonmatsu et al. 2006). However, subsequent research showed highly divergent patterns across the five cities of the experiment (Burdick-Will et al. 2011). Children from families who moved from the most severely disadvantaged neighborhoods experienced the largest gains in assessments of cognitive skills. These results are consistent with another experimental housing study conducted in Chicago that showed that moving out of high-poverty housing projects had substantively large effects on standardized test performance (Ludwig et al. 2009). The latest update on families in the MTO experiment did not show the same effects even in the Chicago and Baltimore sites, although a different assessment was used in this survey, making it difficult to know whether effects have faded or whether results are sensitive to the use of a different assessment of cognitive skills (Sanbonmatsu et al. 2011). As the researchers who drafted the final report evaluating the MTO program noted, the change in findings found in the final evaluation also may be attributable to the fact that the initial changes in neighborhood environments experienced by families in the Chicago and Baltimore sites faded away 
by the time of the final evaluation. As noted in the final report, "over time from the interim to the long-term study in MTO, the neighborhood conditions in which Baltimore and Chicago families lived became more similar to what we see in the other three cities, and any indication of crosssite differences in MTO impacts on test scores attenuates" (Sanbonmatsu et al. 2011:258).

Although the studies based on experimental evidence are not designed to offer evidence on the mechanisms linking neighborhood poverty and educational outcomes, an exploratory analysis of the divergent interim findings from MTO provides insights that are highly relevant for the current study. Using the results from the different treatment and control groups in the five cities in MTO, Burdick-Will et al. (2011) examine several different possible reasons why the experiment initially generated large impacts in some sites but not others. Their exploratory findings suggest that variation in school quality generated by the experiment does not help explain the divergence in treatment effects across the five cities, but variation in exposure to community violence emerges as a more plausible explanation. Children experienced the largest boost in test scores in the cities where the experiment induced the greatest changes in exposure to community violence.

This conclusion is consistent with both quantitative and ethnographic research focusing attention on the role of violence as a mediator between neighborhood disadvantage and academic outcomes (Harding 2009, 2010). It is a conclusion that also is consistent with a large literature from developmental psychology, which finds evidence that community violence affects a range of developmental outcomes across social-emotional, behavioral, and cognitive domains (Osofsky 1999; Shahinfar, Kupersmidt, and Matza 2001; Margolin and Gordis 2004; Bingenheimer et al. 2005). Similar to other traumatic experiences (such as maltreatment), exposure to neighborhood violence and danger are associated with lower performance on assessments of reading, cognitive skills, grade point average, and school attendance (Bowen and Bowen 1999; Delaney-Black 2002; Hurt et al. 2001). School-based violence is inversely associated with high school graduation and four-year college attendance rates; students in moderately violent schools are 5.1 percentage points less likely to graduate than those in low-violence schools, whereas students in seriously violent schools are 15.9 percentage points less likely to attend a four-year college (Grogger 1997).

\section{A Conceptual Model of Acute Environmental Stress and Educational Inequality}

Despite consistent evidence of a negative relationship between community violence and academic achievement, this literature has made limited progress in overcoming the problem of selection bias and in specifying the mechanisms by which violence in the community translates into poor performance at school. The conceptual model presented in this article thus begins with a somewhat obvious question: What happens to children in violent neighborhoods that affects them in school? Although there are many possible answers to this question, one starting point is to consider how children are affected when specific incidents of violence take place in their environment.

Drawing on research from developmental psychology, sociology, and neuroscience, we argue that living in a violent environment is linked with long-term academic trajectories through a sequence of short-term physiological, social, and academic pathways, as depicted in Figure 1. The initial argument represented in Figure 1 is that living in a violent environment affects academic trajectories because of the microprocesses that unfold in the aftermath of incidents of violent crime. When a violent crime (or other environmental stressor) occurs, individual responses may include activation of the stress response system (McEwen and Sapolsky 1995) and emotional responses such as fear and anxiety (LeDoux 2000). These physiological and emotional responses to acute environmental stress are hypothesized to be linked with outcomes related to cognitive functioning and behavior through their impact on symptoms of acute stress disorder (e.g., inability to concentrate, difficulty sleeping), psychosocial effects (e.g., internalizing or externalizing behaviors, aggression), or other coping mechanisms (e.g., substance abuse or dissociation) (Buka et al. 2001; Martinez and Richters 1993; Pynoos et al. 1987). These responses are encompassed as "individual responses" in the figure. 


\section{Long-term associations}

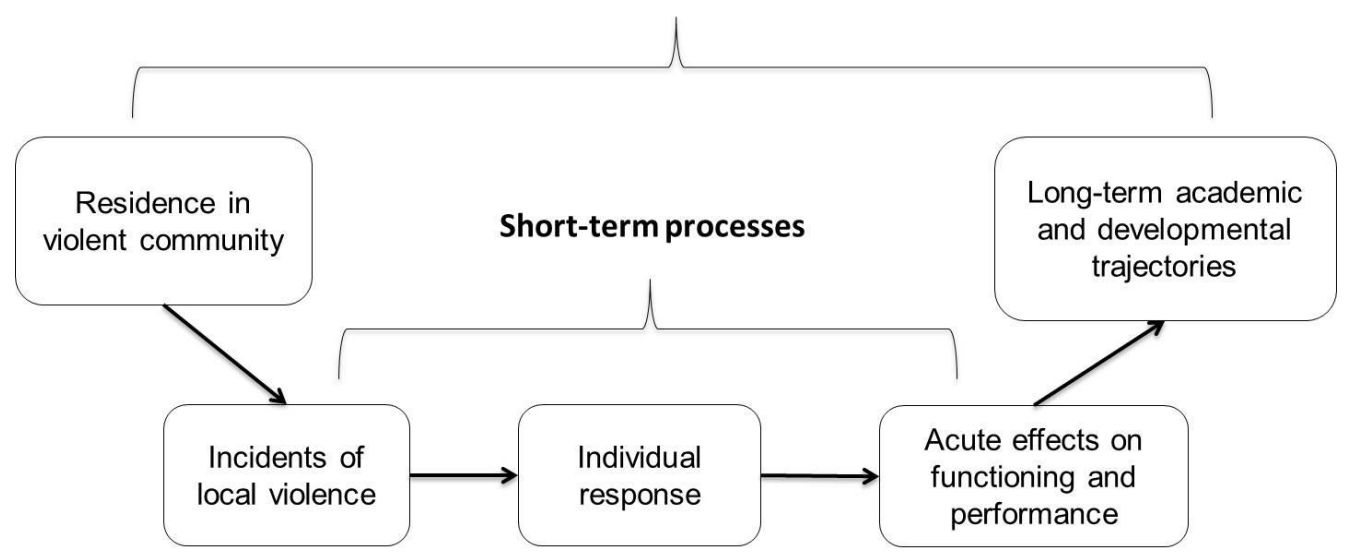

Figure 1: A conceptual model of the short-term processes linking residence in a violent neighborhood with students' long-term academic and developmental trajectories.

Recent research focusing on exposure to local homicides provides evidence to support the idea that specific incidents of extreme violence have a negative effect on children's cognitive functioning and self-regulatory behavior (Sharkey 2010; Sharkey et al., 2012). In a study based on data from children in Chicago, Sharkey (2010) finds that African American children who are given cognitive assessments at home within a week of a homicide in their block group score substantially lower than other youths in the same neighborhood who are assessed at a different time. That study provides convincing evidence that cognitive functioning is impaired in the aftermath of local violence, but it does not reveal whether these effects translate into poor performance at school. The outcomes under study in the previous research are assessments of cognitive skills administered as part of a longer survey protocol conducted in children's homes in Chicago. There are no consequences for poor performance, and no pressure from parents, teachers, or school administrators is placed on children to perform. The comfort and emotional support of the home setting may dampen the potential effect on performance compared to a less supportive and higher stakes setting at school. Alternatively, the effects of local violence may be amplified in the home setting because of the proximity to the violence or to the familial or social connections to the victims or perpetrators. In comparison, the school setting may serve as a "safe haven" for students, providing a setting that allows students to create separation from the violent incident and to shift their attention to academic activities. In short, theory suggests mechanisms through which the impact of violence may be greater or weaker at home relative to school - if the effects are similar or greater at school, this finding would have important implications for educational testing policies.

The current study tests the hypothesized connection leading from environmental stress to poor academic performance. In doing so, the goal of the analysis is not to provide empirical evidence on all pieces of the conceptual model but rather to make the link between environmental stress arising from local violent crime and achievement in school. If the consequences of environmental stress do not translate into impaired performance in school, then there is less urgency to focus on how daily stressors occurring in children's environments affect their functioning on a day-today basis. Alternatively, if the evidence of acute effects of violence exposure does translate into impaired performance in school, then the implications of the research become highly relevant for the literature on educational inequality. Because virtually all of the empirical research on violence and academic achievement has focused on the association between long-term rates of community violence and trajectories of academic 
achievement, the day-to-day microprocesses that link exposure to community violence with educational inequality have been left unspecified and untested in the literature.

We argue that a complete theory linking community violence with academic achievement must begin by studying what happens to children living in violent environments that leads to poor performance in school. Although our analysis only considers the short-term effects of violent crime, we conclude by considering the long-term implications of our results, as shown in the last component of Figure 1. If there is evidence that exposure to incidents of violent crime leads to short-term disruptions of learning or deficits in academic performance, then a natural implication is that children exposed to numerous incidents of violence over the course of a school year are likely to function at a consistently low level over the school year. If estimates of acute effects are taken at face value, then the simple accumulation of acute disruptions to academic performance translates into consistent deficits in academic performance, with long-term consequences for academic trajectories. The conclusion to the article considers how the findings relating to acute effects may translate into longer-term effects on academic trajectories, with implications for the literature on educational inequality.

\section{Analytic Strategy: An Acute Effects Model}

Our primary interest in the empirical analysis is to obtain unbiased causal estimates of the acute effect of exposure to violent crime on student academic performance on statewide ELA and math exams given in grades 3 to $81^{1}$ We do so using a

\footnotetext{
${ }^{1}$ These exams are given over a one- to two-day period, with some variation in the specific exam date by subject and grade. The testing calendar differs slightly across school years, providing variation in the administration timing over our study period. In the $2004 / 2005$ school year, the ELA exam was given to students in eighth grade in mid-January, to fourth graders at the end of January, and to students in grades 3, 5, 6, and 7 in April. The math exams in the same year were administered in April for most grades and in May for the "high-stakes" grade levels (4 and 8). In the following years, administration dates have been grouped by grade, with third, fourth, and fifth grades taking exams on the same dates and sixth, seventh, and eighth grades taking exams on the
}

regression discontinuity design in which we identify the impact by comparing the performance of students exposed to crime in the one-week window before the test to the performance of those exposed in the week following the exam. Intuitively, the timing of the test effectively randomly assigns students to a "treatment" group, those exposed just before the exam, and a "control" group, those exposed just after. We treat a student as "exposed" if a crime has occurred on his or her residential blockface during the specified window of time. The term exposed is used in an analytic way and not in a literal way - we do not intend to imply that every student in the exposed group has witnessed an incident of violent crime directly. It is possible that students who are not exposed may also be affected because they live nearby and/or attend the same schools as the exposed students. In this context, this possibility would lead to estimates that are biased toward zero ${ }^{2}$ Comparing the performance of these groups will yield an unbiased estimate of the causal effect if the precise timing of the violent crime within the one-week window is not systematically related to student ability or other factors that drive academic performance.

To be concrete, we estimate a regression model linking student achievement to individual student characteristics and a measure of exposure to violent crime:

$$
Y_{i t}=\alpha_{i t}+\beta \mathbf{X}_{i t}+\gamma \operatorname{EXPOSED}_{i t}+\theta_{g}+\varepsilon_{i t}
$$

where $Y_{i t}$ is the test outcome (test taking, $z$ score, or passing) for student $i$ on a standardized assessment in academic year $t ; \mathbf{X}_{i t}$ is a vector of student sociodemographic variables and program participation characteristics. These include a set of indicator variables for race/ethnicity, gender, eligibility for free/reduced price lunch (measure of poverty), English proficiency participation in special education programs, and in some models, performance on last year's exam. We also include a set of grade fixed effects, $\theta_{g}$. As shown, we allow for year-specific intercepts $\left(\alpha_{i t}\right)$. Our primary

same dates. In the most recent year, 2009/2010, all ELA exams were administered in April, and math exams were administered in May. Specific exam dates are available from the authors.

${ }^{2}$ In our specifications, bias would arise only if students in neighboring blockfaces were exposed to violent crime in the week after the exam, and thus they are part of the control group. 
variable of interest is EXPOSED, which takes a value of 1 if the student was exposed to a violent crime (homicide or felony assault) in the one-week window prior to the assessment. In Equation (1), $\varepsilon_{i t}$ is a random error term.

The model is estimated using only the sample of students living on blockfaces where violent crimes occurred either one week before or one week after the test, so the coefficient on EXPOSED captures the regression-controlled difference in test scores between students exposed to violence the week before an exam to those exposed within the week after. This can be interpreted as the causal effect of exposure to violence on student performance if the timing of exposure within the window is random. To the extent that crime distracts students or otherwise impedes performance on standardized tests, we expect $\gamma$ to be negative; exposure to crime prior to the test is expected to reduce student achievement ceteris paribus.

We measure three student outcomes. First, we estimate the impact on test taking using a dichotomous variable that takes a value of 1 if the student takes the exam as scheduled. If students are exposed to violent crimes immediately prior to the assessment date, they simply may not attend school, owing to the psychological toll of the incident or the fear of additional violence. Second, we estimate the impact on students' performance on third-grade to eighth-grade ELA and math exams, using $z$-scores ${ }^{3}$ Third, we examine the impact on the likelihood a student passes the scheduled exams using a dichotomous variable that takes a value of 1 if the student earns a passing score. Performance on mandated tests is an important and commonly used measure of student achievement. Furthermore, these tests form the basis for determining New York City school accountability grades, whether a school meets federal adequate yearly progress standards, and whether a student qualifies for a gifted and talented program (or is required to attend summer school).

The model is estimated using the sample of students exposed to a crime on their blockfaces within one week of the standardized tests. We estimate this model both for annual cross sections

\footnotetext{
${ }^{3}$ Test scores are measured as $z$-scores, standardized across students in that grade citywide to mean 0 and standard deviation 1 .
}

of data and in a pooled model (including year fixed effects). Furthermore, to improve the precision of our estimates, we estimate "value-added" models of student performance, including student $i$ 's test score in the previous year as a regressor to control for prior performance 4

Because the impact of crime may vary with student characteristics and/or neighborhood context, we explore heterogeneity in impacts across subgroups. First, on the basis of findings from previous research suggesting that the impact of local violence is stronger for African Americans than for other racial and ethnic groups (Sharkey 2010), we include interactions by race and ethnicity, estimating different impacts for blacks, whites, Asians, Hispanics, and students who identify as an "other race/ethnicity." Second, because previous research has found significant differences in the impact of neighborhood effects on mental health and risky behaviors between girls and boys (Kling, Liebman, and Katz 2007; Kling, Ludwig, and Katz 2005), we include models stratified by gender. Third, we test for differential responses by student grade level, using a set of interaction variables. These models are exploratory, as we do not have a clear prior about whether the effects of local violence are likely to be stronger for older versus younger students. For older students, it is possible that incidents of violence may be more salient or that they may know the individuals involved with the incident personally, thus leading to more pronounced effects. It is also possible that cumulative exposure to incidents of violence over time and/or greater experience with test taking may lessen the acute effect of exposure on achievement.

Finally, because exposure to violence may have a different impact on students who live in higher-poverty, lower-resource neighborhoods than on students who live in higher-income areas, we estimate the impact on students who live in highpoverty neighborhoods, which we define as census tracts where the share of population under 18 years old in poverty is above the citywide median in 2000 (21 percent) 5 Students living in highpoverty neighborhoods account for 84 per-

\footnotetext{
${ }^{4}$ We explore also specifications including a set of school fixed effects to control for unobserved differences across schools.

${ }^{5}$ High-poverty tracts are census tracts where the share of population under 18 in poverty is above the citywide median in 2000.
} 


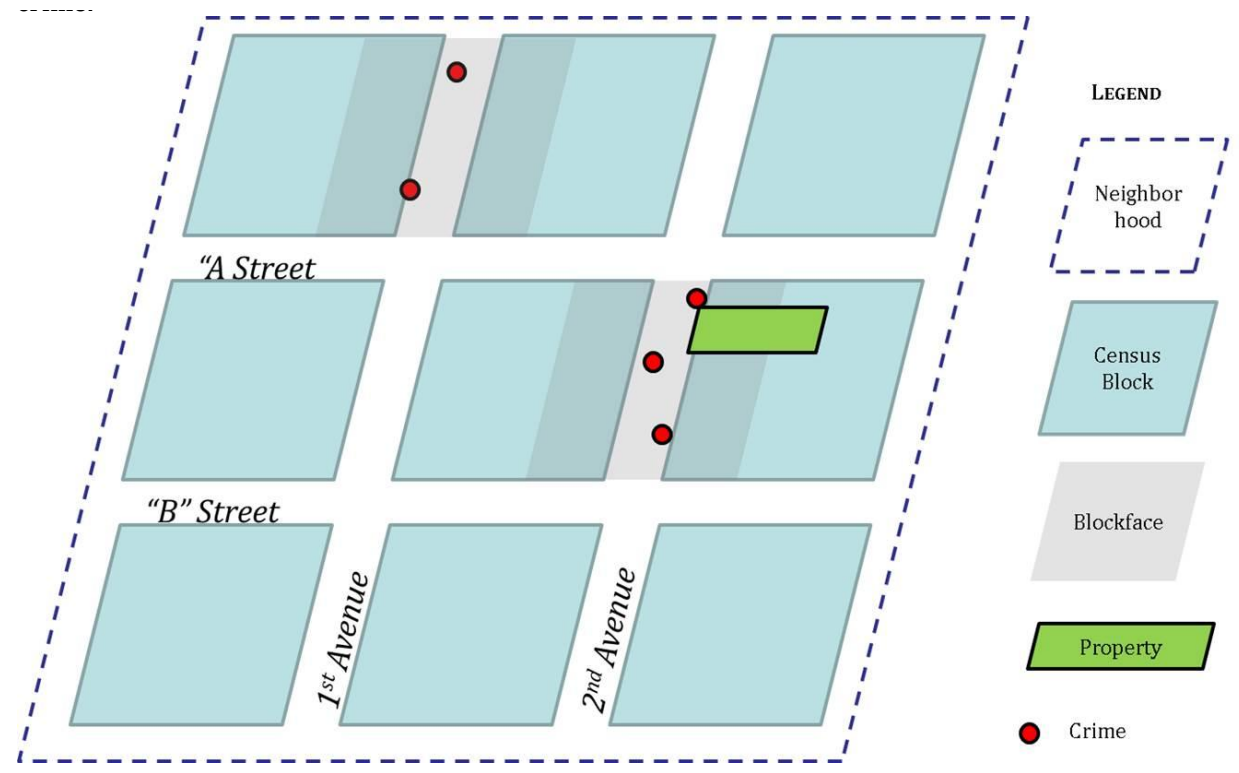

Figure 2: Blockface geography. Students living in the shaded parts of adjacent census blocks would be coded as residing on the same blockface, and would be coded as exposed to the same incidents of crime.

cent of our full sample. This sample restriction allows us to exclude anomalous sections of New York City, such as midtown Manhattan, which is a very wealthy area but also contains a high degree of crime because of the density of commercial and tourist activity in this section of the city.

\section{Data}

We use student-level data from the New York City Department of Education (NYCDOE) and point specific crime data from the New York City Police Department (NYPD) from 2004 to 2010. The point-specific data from the NYPD includes all crimes reported in New York City between 2004 and 2010 and the spatial coordinates, date, time, and offense class and description for each crime. Each year, approximately one-third of these are property crimes, and roughly 8 to 9 percent are violent crimes ${ }^{6}$ We focus our analy-

\footnotetext{
${ }^{6}$ Uniform Crime Reports (UCR) part I violent crimes include murder, manslaughter, robbery, and aggravated assault (forcible rape is omitted from the analysis). UCR part I property crimes include burglary, larceny, motor vehicle theft, and arson. The remaining crime types include
}

sis on exposure to violent crime. Whereas most students are exposed to some type of nonviolent crime near their homes, violent crimes are relatively rare and are likely to be significantly more traumatic.

One critical advantage of these data is our ability to assign each crime incident to a blockface (Figure 2) 7 This level of geographic detail allows us to estimate the impact of exposure to violent crime on the blockface where each student lives. Although we do not know whether a student is a witness to crime, the use of such a small level of geography makes it likely that the residents on the blockface would be aware that a serious violent offense has taken place. We are able to match students with crimes that occur on either side of the blockface on which they live, which is not possible with commonly used block-level

less serious crimes, such as drug use/sales, weapons, simple assault, prostitution, gambling, graffiti, trespassing, disturbing the peace, and moving vehicle violations.

${ }^{7} \mathrm{~A}$ blockface is a street segment bounded by the two closest cross streets and incorporates buildings on both sides of the street, thus allowing us to capture every crime that occurs on the street, regardless of on which side of the street it occurs. We assign the roughly 20 percent of crimes that are reported at intersections to multiple blockfaces. 
data (which include only internal parcels on a full city block).

We use information on the date of the crime, the date of the standardized exam, the spatial coordinates of the crime, and student residential addresses to identify the set of students living on a blockface where a violent crime occurred within a short period before the assessment date (seven days) and the set of students living on a blockface where a violent crime occurred within the same time interval after the exam. More technically, our measure of exposure to violent crime is an indicator variable taking a value of 1 if student $i$ lives on a blockface on which a violent crime occurred within seven days prior to the administration of the standardized exam. We label these students as "exposed" to violent crime in the week before the exam. We focus on a 7-day window of exposure because previous research has found that the acute effect of exposure to incidents of violence appears to fade away within 7 to 10 days following the incident (Sharkey 2010; Sharkey et al., 2012).

Our analysis also draws on a rich longitudinal database from the NYCDOE, containing individual-level data for a complete census of students attending New York City public schools from the 2003/2004 through 2009/2010 academic years. Each student record contains detailed demographic, program, and academic information, including birthplace, race, gender, language ability, poverty, over age for grade, participation in special education and language programs, and performance on standardized ELA and math exams. Importantly, these data also include each student's address of residence, which we geocode to a blockface, with a 99 percent success rate. From this population, we limit our sample to students taking standardized exams in ELA or math in grades 3 to $8^{8}$ who appear in our data for at least three years 9 The NYCDOE student records also include information on test taking

\footnotetext{
${ }^{8}$ We omit high school students from this analysis because they take a different suite of exams. Furthermore, we might expect exposure to violence to affect older youths differently, because they are more likely to be on the street when violence occurs or to know victims and/or offenders.

${ }^{9}$ Of the total 691,159 students who appear in the educational records for three or more years between 2005 and 2010, 22 percent are observed for three years, 27 percent are observed for four years, 32 percent are observed for five years, and 19 percent are observed for six years.
}

and test performance on annual statewide assessments in math and ELA, which we use as our outcome measures. Table 1 shows the total number of students from each racial and ethnic group who are exposed to an incident of violent crime within the week prior to or after the standardized assessments over the full period of the study. Although there is some representation of each of the major racial and ethnic groups in New York City, nearly 90 percent of the sample is African American or Hispanic, consistent with the population of students who attend New York City public schools. Of the students exposed to an incident of violent crime within a week of the assessment, most are only exposed to a single incident. The mean number of exposures is very close to 1 , even though there are students exposed to as many as seven incidents within a week of the assessment.

\section{Results}

\section{Balance between Treatment and Control Groups}

Our identification strategy rests on the assumption that within a small window, exposure to violence before the exam rather than after the exam is essentially random. Empirically, this assumption suggests there should be no systematic differences between students exposed before and after the exam. Table 2 compares the mean individual characteristics of students in the treatment (exposed the week before the exam) and control groups (exposed the week after the exam) to provide evidence on this assumption. The first panel of Table 2 includes the full sample of students, and the second panel focuses on students living in high-poverty neighborhoods.

In the first panel of Table 2, we see some small differences in the characteristics of students exposed before and after the exams, but there is no evidence that would lead one to worry that those exposed before the exam are systematically disadvantaged or otherwise distinct from those exposed after the exam. There are small differences in the residential borough of students exposed before and after the exams, but these differences are not systematic across exams. Important individual characteristics that are highly correlated with academic performance appear to 
Table 1: Violent Crime Exposures within 7-Day Window, by Race/Ethnicity

\begin{tabular}{llrrrr}
\hline & & \multicolumn{4}{c}{ Full Sample } \\
& & ELA Exam & \multicolumn{2}{c}{ Math Exam } \\
& Before & Obs & Mean & Obs & Mean \\
\hline \multirow{2}{*}{ Black } & After & 9,868 & 1.171 & 9,695 & 1.100 \\
& Before & 9,010 & 1.115 & 10,500 & 1.121 \\
Hispanic & After & 12,732 & 1.161 & 11,613 & 1.113 \\
& Before & 10,554 & 1.130 & 12,717 & 1.119 \\
\multirow{3}{*}{ Whian } & After & 1,472 & 1.169 & 1,581 & 1.170 \\
& Before & 1,567 & 1.104 & 1,695 & 1.121 \\
Other race & After & 1,109 & 1.096 & 947 & 1.100 \\
& Before & 987 & 1.094 & 1,073 & 1.087 \\
& After & 137 & 1.131 & 128 & 1.109 \\
& & 126 & 1.151 & 141 & 1.135 \\
Black & & & & \\
\multirow{2}{*}{ Hispanic } & Before & & High Poverty & Tracts & \\
& After & 8,975 & 1.178 & 8,554 & 1.110 \\
Asian & Before & 7,835 & 1.123 & 9,546 & 1.127 \\
& After & 11,969 & 1.161 & 10,846 & 1.116 \\
White & Before & 9,748 & 1.134 & 11,998 & 1.123 \\
& After & 1,091 & 1.170 & 1,265 & 1.183 \\
Other race & Before & 1,152 & 1.110 & 1,268 & 1.126 \\
& After & 615 & 1.107 & 624 & 1.088 \\
& Before & 603 & 1.109 & 669 & 1.078 \\
& After & 122 & 1.131 & 109 & 1.128 \\
& & 107 & 1.168 & 121 & 1.149 \\
\hline
\end{tabular}

be balanced between the treatment and control groups, including free and reduced-price lunch, special education status, immigrant status and home language, and whether the student is over age for grade ${ }^{10}$ Overall, differences are small and substantively unimportant. We conducted chi-square analyses of the differences between treatment and control on the student characteristics, and results from these tests show that the

\footnotetext{
${ }^{10} \mathrm{As}$ an additional test, we predict treatment (exposure before the exam) among the students exposed before or after the exam as a function of individual student characteristics for ELA and math. Joint- $F$ tests on the primary characteristics (prior year test score, black, Hispanic, Asian, other, female, free lunch, reduced-price lunch, special education, foreign-born, and English as a second language) show that these predictors are not significantly different than zero. See supplemental Table 1.
}

two groups are similar on demographic characteristics. Still, we include these individual student characteristics in our regressions to control for any random differences in students exposed to violence during the two time windows.

In the full sample, the majority of students exposed before or after the exam live in Brooklyn and the Bronx (approximately 70 percent), with some in Manhattan (approximately 18 percent) and fewer in Queens (11 percent), and with very few in Staten Island (1 percent). The vast majority of students in the exposed sample qualify for free or reduced-price lunch-88 percent of students are eligible for free lunch and 6 percent for reduced-price lunch. Many students in the exposed sample face other hurdles to academic success - over 40 percent speak a language at home other than English, 14 percent are enrolled 
Table 2: Mean Differences in Characteristics of Students Exposed to Violent Crime Before and After Exam

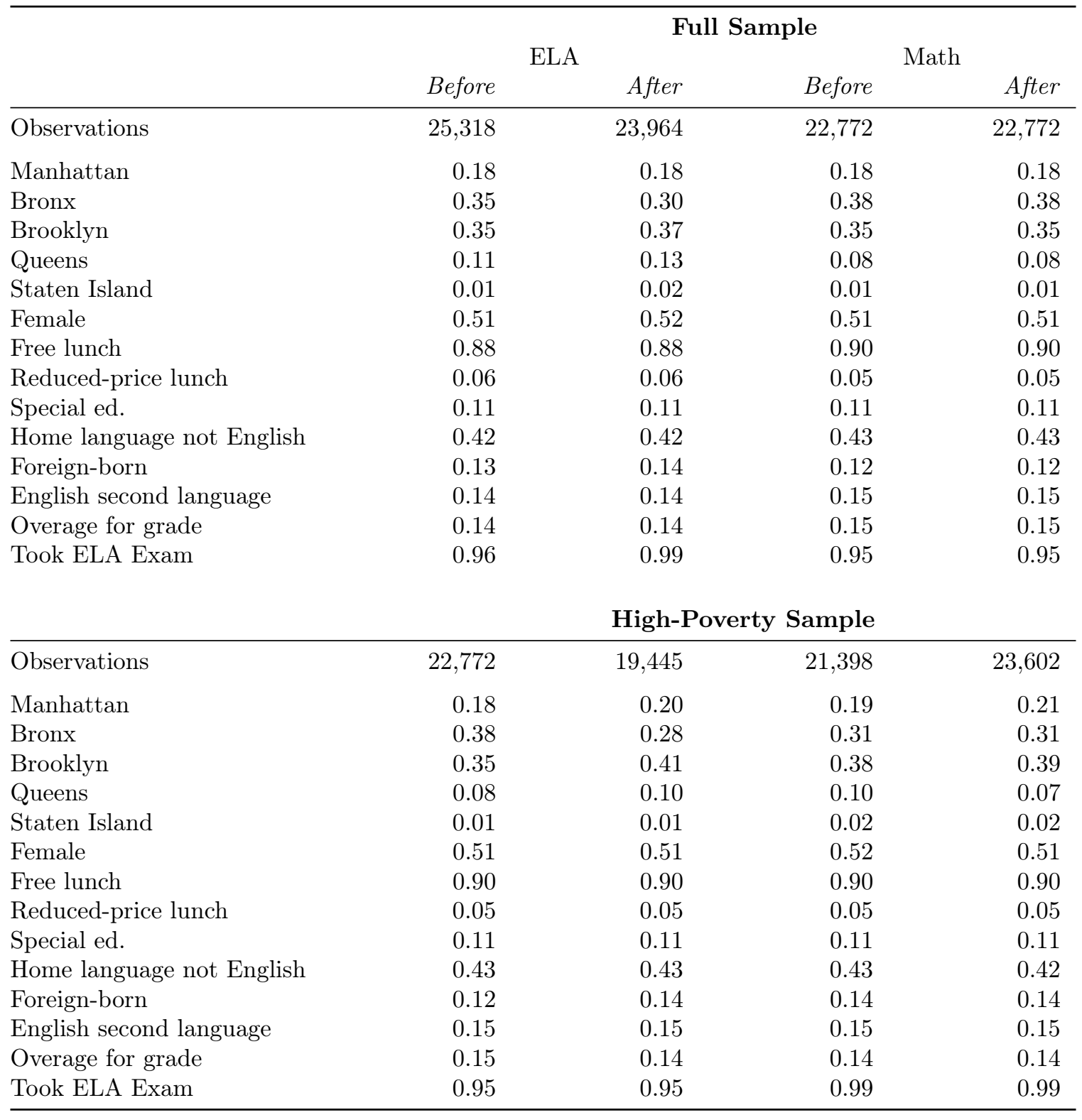


in English as a second language services, and 14 percent are over age for grade. Unsurprisingly, educational disadvantage is more common among students living in higher-poverty neighborhoods (second panel of Table 2). A larger share of students in this sample qualifies for free or reduced-price lunch (95 percent).

\section{Effect of Exposure to Violent Crime on Test Taking}

Exposure to acute neighborhood violence may affect whether a student takes the standardized exam, the score on that exam, and whether the student passes the exam. We examine each of these outcomes in turn. All of the reported results are for the sample of students living in highpoverty neighborhoods, but results are highly similar when examining the full set of students. Linear probability models of the impact of exposure to violent crime on the probability that a student takes the math or ELA exam show no significant impact of exposure to violent crime before the exam on the probability of taking either the math or ELA exams (see supplementary Table 1) compared to exposure after the exam. The point estimates are consistently small and statistically insignificant, and there is little evidence of differential impacts of exposure by race and ethnicity. Students who identify as belonging to other ethnicity or race who are exposed to violent crime in the week prior to the ELA exam are 3.4 percentage points less likely to take the ELA exam compared to students who identify as belonging to other ethnicity or race group who are exposed to violent crime in the week directly following the exam, although the estimated effect is only marginally significant. Overall, it is not surprising that we find that exposure has little impact on test-taking behavior given the extremely high rates of test taking within the sample (between 95 and 99 percent; see Table 2).

\section{Effect of Exposure to Violent Crime on Test Scores}

Although exposure to violence does not affect whether students sit for exams, it does appear to influence how they fare on the exams. Results from the models of the impact of exposure to violent crime on standardized test scores are presented in Table 3. Overall, exposure to violent crime in the seven days prior to the ELA exam decreases test scores by 0.026 standard deviations, on average, compared to exposure in the week following the exam (column 1). Exposure to violent crime appears to have no effect on math performance, however (column 4).

Allowing for differential effects by race (column 2), black students who are exposed to violent crime prior to the ELA exam perform 0.058 standard deviations below their black peers who are exposed in the week after the exam 11 There are no statistically significant effects on ELA performance for any of the other racial or ethnic groups. The effect of exposure to violence is equivalent to roughly 13 percent of the estimated black-white test score gap on reading exams ${ }^{12}$ There are no significant effects on math test performance for any group. Controlling for prior performance in the subject dampens the main results somewhat (column 3), but the negative impact of exposure to violent crime on black students persists and remains statistically significant. In this specification, the impact of exposure to violent crime on ELA test scores for black students is equivalent to 18 percent of the estimated black-white test score gap. Once again, we see no effects on math test scores.

On the basis of prior research suggesting that girls and boys may respond differently to environmental and neighborhood factors, we present additional results testing for gender interactions in Table 4 . The results of models stratified by gender show negative effects of exposure to violent crime on ELA test scores for both boys and girls that are similar in magnitude. Only the coefficient for girls is statistically significant, but the difference in the effects by gender is not statistically significant. Boys exposed to violent crime in the week prior to the exam score 0.018 standard deviations

\footnotetext{
${ }^{11}$ The coefficients on the interaction terms represent within-subgroup comparisons. For instance, the coefficient on Exposure $\times$ Black is an estimate of the effect for black students who are exposed prior to the exam, relative to the effect for black students who are exposed after the exam.

${ }^{12}$ The point estimate on the interaction term $(0.0582)$ is 12.9 percent of the point estimate on "black" (0.452), which represents the black-white gap in performance in this sample because "white" is the reference category.
} 
Table 3: Covariate Models (School Years 2004/2005 to 2009/2010): Impact of Exposure to Violent Crime $^{a}$ and in a High-Poverty Sample ${ }^{b}$

\begin{tabular}{|c|c|c|c|c|c|c|}
\hline \multirow{2}{*}{$\begin{array}{l}\text { 7-day window } \\
\text { DV: Z score }\end{array}$} & \multicolumn{3}{|c|}{ ELA } & \multicolumn{3}{|c|}{ Math } \\
\hline & (1) & $(2)$ & (3) & (1) & $(2)$ & (3) \\
\hline Exposed before & $\begin{array}{r}-0.026^{*} \\
(0.011)\end{array}$ & & & $\begin{array}{c}-0.003 \\
(0.010)\end{array}$ & & \\
\hline \multicolumn{7}{|l|}{ Within-subgroup comparison ${ }^{\mathrm{c}}$} \\
\hline Exposed $\times$ Black & & $\begin{array}{r}-0.058^{\dagger} \\
(0.016)\end{array}$ & $\begin{array}{r}-0.033^{\dagger} \\
(0.011)\end{array}$ & & $\begin{array}{c}0.013 \\
(0.015)\end{array}$ & $\begin{array}{c}0.015 \\
(0.012)\end{array}$ \\
\hline Exposed $\times$ Hispanic & & $\begin{array}{c}-0.002 \\
(0.013)\end{array}$ & $\begin{array}{c}-0.010 \\
(0.011)\end{array}$ & & $\begin{array}{c}-0.013 \\
(0.013)\end{array}$ & $\begin{array}{r}-0.004 \\
(0.009)\end{array}$ \\
\hline Exposed $\times$ Asian & & $\begin{array}{c}0.003 \\
(0.049)\end{array}$ & $\begin{array}{c}0.016 \\
(0.036)\end{array}$ & & $\begin{array}{c}-0.035 \\
(0.042)\end{array}$ & $\begin{array}{c}-0.009 \\
(0.032)\end{array}$ \\
\hline Exposed $\times$ White & & $\begin{array}{c}-0.051 \\
(0.068)\end{array}$ & $\begin{array}{c}-0.012 \\
(0.054)\end{array}$ & & $\begin{array}{l}0.029 \\
(0.055)\end{array}$ & $\begin{array}{r}-0.022 \\
(0.039)\end{array}$ \\
\hline Exposed $\times$ Other & & $\begin{array}{r}-0.015 \\
(0.108)\end{array}$ & $\begin{array}{c}-0.128 \\
(0.099)\end{array}$ & & $\begin{array}{r}-0.055 \\
(0.118)\end{array}$ & $\begin{array}{r}-0.058 \\
(0.083)\end{array}$ \\
\hline Z-score(t-1) & & & $\begin{array}{r}0.581^{\dagger} \\
(0.007)\end{array}$ & & & $\begin{array}{r}0.683^{\dagger} \\
(0.005)\end{array}$ \\
\hline Black & $\begin{array}{r}-0.457^{\dagger} \\
(0.037)\end{array}$ & $\begin{array}{r}-0.452^{\dagger} \\
(0.056)\end{array}$ & $\begin{array}{r}-0.189^{\dagger} \\
(0.041)\end{array}$ & $\begin{array}{r}-0.476^{\dagger} \\
(0.030)\end{array}$ & $\begin{array}{r}-0.468^{\dagger} \\
(0.035)\end{array}$ & $\begin{array}{r}-0.201^{\dagger} \\
(0.026)\end{array}$ \\
\hline Hispanic & $\begin{array}{r}-0.417^{\dagger} \\
(0.036)\end{array}$ & $\begin{array}{r}-0.444^{\dagger} \\
(0.055)\end{array}$ & $\begin{array}{r}-0.178^{\dagger} \\
(0.041)\end{array}$ & $\begin{array}{r}-0.379^{\dagger} \\
(0.029)\end{array}$ & $\begin{array}{r}-0.359^{\dagger} \\
(0.034)\end{array}$ & $\begin{array}{r}-0.162^{\dagger} \\
(0.024)\end{array}$ \\
\hline Asian & $\begin{array}{c}0.042 \\
(0.043)\end{array}$ & $\begin{array}{c}0.015 \\
(0.064)\end{array}$ & $\begin{array}{c}0.010 \\
(0.047)\end{array}$ & $\begin{array}{r}0.312^{\dagger} \\
(0.037)\end{array}$ & $\begin{array}{r}0.344^{\dagger} \\
(0.046)\end{array}$ & $\begin{array}{r}0.107^{\dagger} \\
(0.034)\end{array}$ \\
\hline Other Race & $\begin{array}{r}-0.429^{\dagger} \\
(0.064)\end{array}$ & $\begin{array}{r}-0.447^{\dagger} \\
(0.091)\end{array}$ & $\begin{array}{r}-0.161^{*} \\
(0.079)\end{array}$ & $\begin{array}{r}-0.455^{\dagger} \\
(0.065)\end{array}$ & $\begin{array}{r}-0.415^{\dagger} \\
(0.097)\end{array}$ & $\begin{array}{r}-0.109 \\
(0.068)\end{array}$ \\
\hline Constant & $\begin{array}{r}0.461^{\dagger} \\
(0.051)\end{array}$ & $\begin{array}{r}0.474^{\dagger} \\
(0.067)\end{array}$ & $\begin{array}{r}0.539^{\dagger} \\
(0.056)\end{array}$ & $\begin{array}{r}0.446^{\dagger} \\
(0.040)\end{array}$ & $\begin{array}{r}0.431^{\dagger} \\
(0.043)\end{array}$ & $\begin{array}{r}0.786^{\dagger} \\
(0.044)\end{array}$ \\
\hline Observations & 39,322 & 39,322 & 32,707 & 43,043 & 43,043 & 36,719 \\
\hline$R^{2}$ & 0.176 & 0.177 & 0.474 & 0.17 & 0.172 & 0.554 \\
\hline Grade Fixed Effects & Yes & Yes & Yes & Yes & Yes & Yes \\
\hline Year Fixed Effects & Yes & Yes & Yes & Yes & Yes & Yes \\
\hline Clustered S.E. (blockface level) & Yes & Yes & Yes & Yes & Yes & Yes \\
\hline
\end{tabular}

${ }^{a}$ Controlling for race/ethnicity, female, free lunch, reduced-price lunch, special education, home language not English, foreign-born, limited English-proficient, and over-age-for-grade.

$\mathrm{b}$ The sample includes all students in high-poverty tracts who were exposed within seven days before or after the exam, and who took the exam in that year. High-poverty defined as residing in a census tract with a child poverty rate at or above the median.

${ }^{c}$ The coefficients on the interaction terms represent within-subgroup comparisons between students exposed to violent crime before the exam, relative to students exposed after the exam.

${ }^{*} p<0.05 \dagger p<0.01$.

Note: Standard errors in parentheses. 
below boys who are exposed in the week following the exam, and girls exposed before score 0.021 standard deviations lower than girls exposed the following week. Consistent with our previous findings, there are no effects on math scores, and the models including interaction terms by race and ethnicity show that the effects are largest for black boys and girls. Exposure to violent crime results in black boys scoring 0.034 standard deviations below black boys who are exposed after the exam, and black girls score 0.032 standard deviations lower than black girls exposed in the following week. These score deficits are equal to 17 percent of the black-white test score gap for both boys and girls.

The magnitude of the impact of exposure to violence on achievement also may vary by student age and grade. Table 5 presents results of the models stratified by grade level, grouping elementary grades 3, 4, 5 and middle school grades 6 , 7 , and 8 . The results clearly show that students in the elementary grades experience a large and significant decrease in ELA test scores following exposure to violent crime on the blockface. Students in the elementary grades who are exposed to violent crime prior to the exam score 0.032 standard deviations lower on the ELA exam compared to elementary school students exposed in the week following the exam. Again, the effect is largest for black elementary school studentsexposed black elementary school students score 0.060 standard deviations below black elementary school students exposed in the week after the exam. This effect is equal to over 30 percent of the black-white test score gap among elementary school students. However, there is no acute effect of exposure to violent crime on ELA test scores for middle school students, with the exception of those who identify as belonging to an other race or ethnicity. There are no effects of exposure to violence on math test scores by student grade level.

The finding of stronger effects for elementary school students on the ELA exam may be because older students have more schooling and test-taking experience and are less affected by outside factors compared to younger students. Alternatively, this finding may suggest that events occurring near the home of middle school students are less salient when they enter the school setting. In New York City, middle schools typ- ically are larger and draw from a much larger catchment area than elementary schools. Events that occur on one student's blockface may be relevant for that student but quickly forgotten once the student enters school and begins to interact with peers from other neighborhoods. It may be more difficult for an elementary school student to put an incident of violent crime behind the student if many of the student's peers are from the same block or neighborhood and also witnessed or heard about the same event.

\section{Effect of Exposure to Violent Crime on Test Failure}

Perhaps the most telling measure of student success is whether the student's test score represents a pass or a fail. Table 6 presents the results from linear probability models of passing both the ELA and math exams. Overall, exposure to violent crime in the week before the ELA exam decreases the probability of passing that exam by 1.1 percentage points, compared to peers who are exposed in the week after the exam (column 1). Results from specifications including race/ethnic group interactions shown in column 2 indicate much stronger effects for black students. Exposure to violent crime has no apparent effect on any of the racial/ethnic groups other than blacks. Black students who are exposed to violent crime in the week prior to the exam are 2.8 percentage points less likely to pass the exam than black students exposed to violent crime in the week following the exam, an effect size equivalent to 18 percent of the black-white gap in ELA passing rates ${ }^{13}$ Consistent with the previous results, there is no significant effect of exposure to violent crime on the probability of passing the math exam.

\section{Robustness Tests}

The results reported here are robust to multiple sensitivity analyses. First, the main effect of exposure to violence in the seven days prior to the exam on ELA test scores is robust to exposure windows of $2,3,4,5,6,14$, and 28 days in length. The effects for black students also are robust to

\footnotetext{
${ }^{13}$ Models limiting the sample to students who took the exam show the same pattern of results and slightly larger effect sizes. See supplementary Table 1.
} 
Table 4: Gender Models (School Years 2004/2005 to 2009/2010): Impact of Exposure to Violent Crime ${ }^{a}$ and in a High-Poverty Sample ${ }^{b}$

\begin{tabular}{|c|c|c|c|c|}
\hline \multirow{2}{*}{$\begin{array}{l}\text { 7-day window } \\
\text { DV: Z-score ELA }\end{array}$} & \multicolumn{2}{|c|}{ Males } & \multicolumn{2}{|c|}{ Females } \\
\hline & (1) & $(2)$ & (3) & (4) \\
\hline Exposed Before & $\begin{array}{c}-0.018 \\
(0.011)\end{array}$ & & $\begin{array}{r}-0.021^{*} \\
(0.010)\end{array}$ & \\
\hline \multicolumn{5}{|l|}{ Within-subgroup comparison ${ }^{c}$} \\
\hline Exposed $\times$ Black & & $\begin{array}{r}-0.034^{*} \\
(0.017)\end{array}$ & & $\begin{array}{r}-0.032^{*} \\
(0.015)\end{array}$ \\
\hline Exposed $\times$ Hispanic & & $\begin{array}{c}-0.011 \\
(0.015)\end{array}$ & & $\begin{array}{c}-0.011 \\
(0.014)\end{array}$ \\
\hline Exposed $\times$ Asian & & $\begin{array}{c}0.032 \\
(0.046)\end{array}$ & & $\begin{array}{c}0.001 \\
(0.058)\end{array}$ \\
\hline Exposed $\times$ White & & $\begin{array}{c}0.031 \\
(0.071)\end{array}$ & & $\begin{array}{c}-0.059 \\
(0.070)\end{array}$ \\
\hline Exposed $\times$ Other & & $\begin{array}{c}-0.172 \\
(0.125)\end{array}$ & & $\begin{array}{r}-0.080 \\
(0.156)\end{array}$ \\
\hline Z-Score $(\mathrm{t}-1)$ & $\begin{array}{r}0.567^{\dagger} \\
(0.009)\end{array}$ & $\begin{array}{r}0.567^{\dagger} \\
(0.009)\end{array}$ & $\begin{array}{r}0.594^{\dagger} \\
(0.009)\end{array}$ & $\begin{array}{r}0.594^{\dagger} \\
(0.009)\end{array}$ \\
\hline Constant & $\begin{array}{r}0.618^{\dagger} \\
(0.065)\end{array}$ & $\begin{array}{r}0.595^{\dagger} \\
(0.075)\end{array}$ & $\begin{array}{r}0.504^{\dagger} \\
(0.067)\end{array}$ & $\begin{array}{r}0.523^{\dagger} \\
(0.077)\end{array}$ \\
\hline Observations & 15,942 & 15,942 & 16,765 & 16,765 \\
\hline$R^{2}$ & 0.46 & 0.46 & 0.47 & 0.47 \\
\hline Grade Fixed Effects & Yes & Yes & Yes & Yes \\
\hline Year Fixed Effects & Yes & Yes & Yes & Yes \\
\hline Clustered S. E. (blockface level) & Yes & Yes & Yes & Yes \\
\hline
\end{tabular}

${ }^{a}$ Controlling for race/ethnicity, free lunch, reduced-price lunch, special education, home language not English, foreign-born, limited English-proficient, and over-age-for-grade.

$\mathrm{b}$ The sample includes all students in high poverty tracts who were exposed within seven days before or after the exam, and who took the exam in that year. High poverty defined as residing in a census tract with a child poverty rate at or above the median.

${ }^{c}$ The coefficients on the interaction terms represent within-subgroup comparisons between students exposed to violent crime before the exam, relative to students exposed after the exam.

${ }^{*} p<0.05 \dagger p<0.01$.

Note: Standard errors in parentheses.

each of these exposure windows. We prefer the seven-day measure both because prior research has found that the acute effects of local violence persist for roughly 7 to 10 days following the incident (Sharkey 2010; Sharkey et al., 2012) and because crime patterns tend to vary by the day of the week. The seven-day window includes one weekend and all weekdays in the period prior to and after the exam. Second, the results are robust to estimation based on a larger unit of geography- a measure of "contiguous blocks" - that includes all blockfaces that surround a central blockface. The results are highly consistent using this measure, but we prefer the smaller blockface measure because it gives us more confidence that students who live on the street segment were exposed to the crime (either by witnessing or hearing about the crime). Third, the results are robust to estimation using a dosage model that includes a continuous measure of the number of violent as- 
Table 5: Grade Models (School Years 2004/2005 to 2009/2010): Impact of Exposure to Violent Crime ${ }^{a}$ and in a High-Poverty Sample ${ }^{b}$

\begin{tabular}{|c|c|c|c|c|}
\hline \multirow{2}{*}{$\begin{array}{l}\text { 7-day window } \\
\text { DV: Z-score ELA }\end{array}$} & \multicolumn{2}{|c|}{$\begin{array}{c}\text { Elementary } \\
\text { (Grades } 3,4,5)\end{array}$} & \multicolumn{2}{|c|}{$\begin{array}{c}\text { Middle } \\
\text { (Grades 6,7,8) }\end{array}$} \\
\hline & (1) & $(2)$ & (3) & (4) \\
\hline Exposed Before & $\begin{array}{r}-0.032^{*} \\
(0.013)\end{array}$ & & $\begin{array}{c}-0.012 \\
(0.010)\end{array}$ & \\
\hline \multicolumn{5}{|l|}{ Within-subgroup comparison ${ }^{c}$} \\
\hline Exposed $\times$ Black & & $\begin{array}{r}-0.060^{\dagger} \\
(0.019)\end{array}$ & & $\begin{array}{c}-0.016 \\
(0.014)\end{array}$ \\
\hline Exposed $\times$ Hispanic & & $\begin{array}{r}-0.020 \\
(0.017)\end{array}$ & & $\begin{array}{r}-0.005 \\
(0.012)\end{array}$ \\
\hline Exposed $\times$ Asian & & $\begin{array}{c}0.041 \\
(0.053)\end{array}$ & & $\begin{array}{c}0.000 \\
(0.048)\end{array}$ \\
\hline Exposed $\times$ White & & $\begin{array}{l}0.040 \\
(0.077)\end{array}$ & & $\begin{array}{r}-0.070 \\
(0.070)\end{array}$ \\
\hline Exposed $\times$ Other & & $\begin{array}{c}0.022 \\
(0.163)\end{array}$ & & $\begin{array}{r}-0.294^{*} \\
(0.128)\end{array}$ \\
\hline Z-Score(t-1) & $\begin{array}{r}0.590^{\dagger} \\
(0.010)\end{array}$ & $\begin{array}{r}0.589^{\dagger} \\
(0.010)\end{array}$ & $\begin{array}{r}0.575^{\dagger} \\
(0.009)\end{array}$ & $\begin{array}{r}0.575^{\dagger} \\
(0.009)\end{array}$ \\
\hline Constant & $\begin{array}{r}0.574^{\dagger} \\
(0.064)\end{array}$ & $\begin{array}{r}0.534^{\dagger} \\
(0.074)\end{array}$ & $\begin{array}{r}0.172^{\dagger} \\
(0.044)\end{array}$ & $\begin{array}{r}0.197^{\dagger} \\
(0.058)\end{array}$ \\
\hline Observations & 13,450 & 13,450 & 19,257 & 19,257 \\
\hline$R^{2}$ & 0.45 & 0.45 & 0.49 & 0.49 \\
\hline Grade Fixed Effects & Yes & Yes & Yes & Yes \\
\hline Year Fixed Effects & Yes & Yes & Yes & Yes \\
\hline Clustered S.E. (blockface level) & Yes & Yes & Yes & Yes \\
\hline
\end{tabular}

${ }^{a}$ Controlling for race/ethnicity, female, free lunch, reduced-price lunch, special education, home language not English, foreign-born, limited English-proficient, and over-age-for-grade.

$\mathrm{b}$ The sample includes all students in high poverty tracts who were exposed within seven days before or after the exam, and who took the exam in that year. High poverty defined as residing in a census tract with a child poverty rate at or above the median.

${ }^{c}$ The coefficients on the interaction terms represent within-subgroup comparisons between students exposed to violent crime before the exam, relative to students exposed after the exam.

${ }^{*} p<0.05 \dagger p<0.01$.

Note: Standard errors in parentheses.

saults or homicides occurring on the blockface, instead of a binary exposure measure. Fourth, the results focus on the sample of students who reside in neighborhoods that have child poverty rates higher than the citywide median neighborhood. We selected this sample to facilitate a comparison between students who live in similarly disadvantaged neighborhoods. However, our results are robust to estimation of all of the models on the full sample of exposed students.

Finally, we estimated a set of additional models including school fixed effects and census tract fixed effects, respectively. These models make comparisons among students within the same schools or census tracts who are exposed before and after the exam period. In these models, the 
Table 6: Pass Exam Models (School Years 2004/2005 to 2009/2010): Impact of Exposure to Violent Crime $^{a}$ and in a High-Poverty Sample ${ }^{b}$

\begin{tabular}{|c|c|c|c|c|}
\hline \multirow[b]{2}{*}{ 7-day window } & \multicolumn{2}{|c|}{ Pass ELA } & \multicolumn{2}{|c|}{ Pass Math } \\
\hline & (1) & $(2)$ & $(3)$ & $(4)$ \\
\hline Exposed Before & $\begin{array}{r}-0.011^{*} \\
(0.006)\end{array}$ & & $\begin{array}{c}0.002 \\
(0.006)\end{array}$ & \\
\hline Within-subgroup comparison ${ }^{d}$ & & & & \\
\hline Exposed $\times$ Black & & $\begin{array}{r}-0.028^{\dagger} \\
(0.009)\end{array}$ & & $\begin{array}{c}0.005 \\
(0.008)\end{array}$ \\
\hline Exposed $\times$ Hispanic & & $\begin{array}{c}-0.002 \\
(0.007)\end{array}$ & & $\begin{array}{c}-0.006 \\
(0.008)\end{array}$ \\
\hline Exposed $\times$ Asian & & $\begin{array}{c}0.029 \\
(0.018)\end{array}$ & & $\begin{array}{r}0.029^{\dagger} \\
(0.017)\end{array}$ \\
\hline Exposed $\times$ White & & $\begin{array}{c}-0.000 \\
(0.028)\end{array}$ & & $\begin{array}{c}0.031 \\
(0.025)\end{array}$ \\
\hline Exposed $\times$ Other & & $\begin{array}{c}-0.042 \\
(0.062)\end{array}$ & & $\begin{array}{c}-0.016 \\
(0.058)\end{array}$ \\
\hline Constant & $\begin{array}{r}0.761^{\dagger} \\
(0.020)\end{array}$ & $\begin{array}{c}0.755^{\dagger} \\
(0.025)\end{array}$ & $\begin{array}{r}0.888^{\dagger} \\
(0.018)\end{array}$ & $\begin{array}{c}0.874^{\dagger} \\
(0.021)\end{array}$ \\
\hline Observations & 41,241 & 41,241 & 43,596 & 43,596 \\
\hline$R^{2}$ & 0.18 & 0.18 & 0.19 & 0.193 \\
\hline Grade FE & Yes & Yes & Yes & Yes \\
\hline Year FE & Yes & Yes & Yes & Yes \\
\hline Cluster SE (blockface level) & Yes & Yes & Yes & Yes \\
\hline
\end{tabular}

${ }^{a}$ Controlling for race/ethnicity, female, free lunch, reduced-price lunch, special education, home language not English, foreign-born, limited English-proficient, and over-age-for-grade.

$\mathrm{b}$ The sample includes all students in high poverty tracts who were exposed within seven days before or after the exam. High poverty defined as residing in a census tract with a child poverty rate at or above the median.

${ }^{\mathrm{c}}$ Models limited to students who took the exam show the same pattern of results, but larger effect sizes (see Supplementary Table 2).

$\mathrm{d}$ The coefficients on the interaction terms represent within-subgroup comparisons between students exposed to violent crime before the exam, relative to students exposed after the exam.

${ }^{*} p<0.05 \dagger p<0.01$.

Note: Standard errors in parentheses.

main effects of exposure to local violence are slightly smaller in magnitude but similar, and the results for black students are similar and statistically significant. We consider both of these models conservative because part of the effects of exposure to violent crime are likely to derive in part from discussion of the violence and fear of continuing violence among students in the larger area or school surrounding the blockface where the crime occurred, meaning there is likely to be contamination of the treatment effect. This bias is present in the main results as well but is likely to be minimal - in the school and census tract fixed effects specifications, this bias is amplified.

\section{Discussion}

Our central finding is that acute exposure to very localized violent crime decreases standard- 
ized test scores in ELA, but not in math. This conclusion is based on comparisons of students who are exposed to one or more incidents of violent crime on their residential blockface in the week prior to the exam to students exposed in the week following the exam. The magnitude of the estimated impact of exposure to violent crime is substantively small in the overall model. However, models including race/ethnicity interactions show that the estimated effects are much larger for black students and are null for other groups. Black students exposed to a violent crime in the week prior to the ELA exam score 0.06 standard deviations lower than those exposed in the week after the exam, an effect size that is 13 percent of the black-white gap in test score performance in our sample. Black students exposed to violent crime are 3 percentage points less likely to pass the ELA exam, an effect size that is equal to 18 percent of the black-white gap in passing rates. Elementary school students exposed to violent crime experience a large decrease in ELA test scores compared to elementary school students exposed after the exam. For black elementary school students, this reduction in test scores is equivalent to over 30 percent of the black-white test score gap. Thus, although the overall effect size is small in magnitude, the impact for specific subgroups is substantial.

The robust identification strategy - which relies on variation in the timing of violent crime incidents relative to test dates - strengthens the internal validity of the estimates and provides confidence in the interpretation of these estimated effects as causal. This approach does not allow for tests of the mechanisms, however, and thus leaves several questions unanswered. The first issue concerns why we find consistent, negative effects of exposure on ELA exam test scores and exam passage, but no effects on math. The strong effects on ELA assessments are consistent with a strand of research on neighborhood effects that finds that neighborhood disadvantage, and community violence in particular, seems to impede the development of language and reading skills and impair performance on tests of verbal or reading skills (Burdick-Will et al. 2011; Kling et al. 2007; Ludwig et al. 2010; Sharkey 2010; Sampson et al. 2008). This finding of a negative effect on ELA test scores but no effect on math also is consistent with findings in several previous studies examining the impact of interventions on academic performance (see, e.g., Ludwig et al. 2001; Levine and Schanzenbach 2009; Wolf et al. 2009).

Researchers have proposed several possible explanations for the long-term effects of exposure to violent or severely disadvantaged environments on development of verbal and language skills, focusing on the importance of verbal interactions within the home or in public space as potential explanations (Sampson et al. 2008). However, these explanations are less applicable for understanding why the acute effects of exposure to violent crime are limited to assessments of English or language skills. Potential explanations may involve the interaction of the physiological responses to stress that arise from exposure to violence and the types of skills that are required to perform well in tests of English or language arts as opposed to tests of math achievement. Liew et al. (2008) suggest that achievement in math and reading may be explained by different self-regulatory mechanisms. We are unable to provide evidence on these possible mechanisms, but we consider this a central question for future research.

A second unresolved question is why we find the largest effects for black students, even though Hispanic students are exposed to violent crime in their neighborhoods at similarly high rates. It is notable that several recent studies analyzing neighborhood effects on test scores are either based on samples composed primarily of African Americans or else show the most pronounced effects for African Americans (Kling et al. 2007; Ludwig et al. 2010; Sharkey 2010; Sampson et al. 2008). We propose two potential explanations for the race/ethnicity interaction. The first is that violence may be particularly salient for African Americans relative to other groups if the victims of violent crimes are disproportionately black (Sharkey 2010). Because we do not know the race/ethnicity of victims in the data, this mechanism is not possible to test. The second potential explanation is that the systems of support for blacks, particularly in the form of counseling and support systems in the school setting, may be different for blacks compared to Hispanics, Asian Americans, or white students. We intend to explore this hypothesis in future research. 
A third question is why we find significant, negative effects for elementary school students (in grades 3,4 , and 5) and no effect on middle school students (grades 6, 7, and 8). We have three speculative hypotheses about this finding. The first relates to the fact that elementary students within the New York City public school system are more likely than middle and high school students to attend a school close to home. Local violence may become more salient, and have a larger effect on students, in school settings where most students are from the same neighborhood and are more aware of local incidents of violence. The second hypothesis is that younger students with less experience taking tests may be more sensitive to factors outside the classroom when taking exams. The acute effect of exposure to violence, therefore, may have a larger effect for these students than for older students, who have more experience with testing. The third hypothesis centers on accumulated exposure to violence. Older students may be less sensitive to the acute effect of exposure to violence if they have had multiple exposures over their lifetimes or regularly in their everyday lives. Therefore, an exposure that might have had large effects when a student was younger may have less of a marginal effect after years living in a neighborhood where crime is common. Even though older students are more likely to be directly involved with or to directly witness crimes, these exposures do not appear to translate into decreases in test scores in the short run.

In addition to these unresolved questions, there are a few limitations of the analysis that are important to acknowledge. The first is that the identification strategy is based on the assumption that there are no differences in unobserved characteristics that are related to academic performance between the groups of students who are exposed to violent crimes before and after the administration of the exams. It is not possible to provide definitive proof that the assumption is valid, but it is difficult to come up with plausible stories as to why students living in streets where violence occurred the week before the exam might differ from students living on streets where violence occurred the week after the exam. Furthermore, the evidence available suggests that there are not systematic, observable differences between the treatment and control groups, providing support for this assumption.

The analysis could be critiqued on the basis of external validity as well, as it is based on data from New York City only. Although we acknowledge the unique features of New York City, we argue that size and diversity of New York's public school system provides lessons that are useful for all urban school systems. New York City is home to the largest school district in the United States, with more than 1 million students and more than 1,600 schools. The sheer size of the public school population enables nuanced analyses of students in various underrepresented subgroups that would be impossible to conduct elsewhere. Still, the findings from the analysis are not generalizable to cities other than New York, and additional research should be conducted in other cities to determine whether the findings presented are replicated in cities of different sizes and with different student populations.

With these limitations and unresolved questions in mind, what are the implications of the findings for educational inequality? In the introductory sections of the article, we described a long-standing debate in the field of education on the role that schools can play in overcoming the disadvantages and burdens associated with student poverty. One perspective in this debate is that the school setting should be viewed as something of a sanctuary, a place where students are separated from the burdens associated with daily life in poor families or in poor communities. This article provides evidence that complicates this perspective.

What this debate lacks is a strong base of evidence identifying what it is about growing up in a disadvantaged family setting or a disadvantaged community setting that affects the performance of children when they enter the school. This article offers evidence about one specific, concrete way in which disadvantage in students' residential environments makes its way into the school setting to affect academic performance. In this way, the analysis moves from the abstract argument that something about growing up in a poor neighborhood setting affects children's performance in school to a more tangible argument that specific incidents occurring on the residential blockfaces of students have a measurable impact on assessments that carry tremendous importance for the 
student, for his or her teacher, and for the school that he or she attends.

In addition to being more tangible and concrete than previous research on neighborhood poverty and academic performance, we argue that the analysis generates more convincing causal estimates than much of the empirical research in the literature. Research on the relationship between neighborhood conditions and academic success typically relies on variation among students living in different neighborhood environments that offer unique sets of risks and resources. The common critique of this literature is that unobserved characteristics of families may affect where families reside and may also affect how students perform in school, thus generating bias because of classic confounding (Kling et al. 2007). Alternatively, the evidence from residential mobility experiments like MTO overcomes the problem of selection bias but generates estimates that are difficult to interpret because they conflate the effect of changing neighborhoods with the effect of residential mobility. Several studies find that moving itself is linked with poor academic outcomes, suggesting that this is not a trivial problem for the experimental literature from mobility programs (Pribesh and Downey 1999; Scanlon and Devine 2001; Swanson and Schneider 1999).

This study exploits variation in the timing of violent crime rather than in exposure to violent crime. In this way, the approach overcomes the problem of selection bias and allows for more convincing causal inferences. Because we focus on a very specific "treatment" of interest, exposure to an incident of violent crime, the interpretation of the meaning of the treatment effect under study is precise. Although we believe the precision in measurement and the identification strategy are the major strengths of the analysis, these strengths also mean that the findings are less informative for making broader conclusions about the long-term consequences of growing up in a violent environment. For instance, the number of students actually exposed to local violent crimes is not large enough to conclude that exposure to incidents of violent crime before standardized exams is a major factor affecting educational inequality. We argue, however, that the findings have implications that go well beyond the specific point estimates from our models.
Although our analysis only considers the shortterm effects of violent crime occurring before statewide exams, students are exposed to similar environmental stressors (including violent crime and many other sources of environmental stress) throughout the year. If taken at face value, our estimates of acute effects suggest that children exposed to repeated incidents of violence over the course of a school year are likely to experience repeated periods of low functioning and low performance over the school year. If students are affected every time an incident of violence occurs on their block, even for a short period of time, then the accumulation of short-term disruptions to functioning and performance are likely to translate into consistent deficits in academic performance, with long-term consequences for academic trajectories. This study does not provide empirical evidence of the last component in Figure 1, which connects the short-term effect of local violence with long-term effects on academic achievement. Instead, the central contributions of the article are to put forth a conceptual model that makes this connection between short-term processes and long-term trajectories, while providing a precise and rigorous analysis demonstrating evidence for one specific way in which living in a violent environment affects a critically important aspect of academic performance. In demonstrating the consequences of violent crime on students' performance on highstakes standardized assessments, this article sets the stage for a larger research agenda focusing on the way that acute stressors alter long-term academic trajectories.

The findings in this study have direct implications pertaining to the weight given to standardized assessments as a means of evaluating not only students but also teachers and schools. Evaluations of New York City teachers, which are based on students' test scores, are published and are used to assess the performance of teachers. The performance of students is an important factor in the grades assigned to schools and in decisions about whether schools require new leadership or whether they should be closed. The finding showing that students' scores are affected by even a single incident of violent crime that occurs close to home reinforces the idea that a tremendous amount of attention is being placed on the performance of students during a single examination 
taken at a single point in time in a specific setting. Violent crimes are only one type of environmental stressor that may impair the performance of students in a manner that systematically affects students, teachers, and administrators in more disadvantaged, violent communities across the city.

Beyond the question of evaluation, by focusing our attention on a very specific type of environmental stressor, we are able to provide a more targeted discussion of policy implications pertaining to students' exposure to violence and other environmental stressors. Policy responses might include training for teachers to expand awareness of the burdens that students carry into the classroom and to respond effectively, or added resources for counselors to provide the support necessary for students from intensely violent residential environments. Additional research should be conducted to determine whether school climate or school safety policies moderate the effects of exposure to violence.

Lastly, it is important to note that this article focuses only on the effects of localized violence occurring in the period prior to standardized assessments, but there is no reason to think that the consequences of exposure to violent crime are limited to standardized test performance. Similar incidents of violence occur on a regular basis and have the potential to alter students' experience in school, making it difficult for them to concentrate on routine tasks in the classroom setting. The results reported in this study should provoke a broader recognition of the burdens that students from violent or chaotic environments bring with them to the classroom and add urgency for school officials and policy makers to address the consequences of community violence for students' academic progress.

\section{References}

Bingenheimer, Jeffrey B., Robert T. Brennan, and Felton J. Earls. 2005. "Firearm Violence Exposure and Serious Violent Behavior." Science 308:1323-26. http://dx.doi.org/10 1126/science.1110096

Bowen, Natasha K. and Gary L. Bowen. 1999. "Effects of Crime and Violence in Neighborhoods and Schools on the School Behavior and Performance of Adolescents." Journal of Adolescent Research 14:319-42. http://dx doi.org/10.1177/0743558499143003

Buka, Stephen L., Theresa L. Stichick, Isolde Birdthistle, and Felton J. Earls. 2001. "Youth Exposure to Violence: Prevalence, Risks and Consequences." American Journal of Orthopsychiatry 71:298-310. http://dx.doi org/10.1037/0002-9432.71.3.298

Burdick-Will, Julia, Jens Ludwig, Stephen Raudenbush, Robert Sampson, Lisa Sanbonmatsu, and Patrick Sharkey. 2011. "Converging Evidence for Neighborhood Effects on Children's Test Scores: An Experimental, Quasiexperimental, and Observational Comparison." Pp. 255-76 in Whither Opportunity? Rising Inequality, Schools, and Children's Life Chances, edited by Greg Duncan and Richard Murnane. New York: Russell Sage.

Delaney-Black, Virginia, Chandice Covington, Steven J. Ondersma, Beth Nordstrom-Klee, Thomas Templin, Joel Ager, James Janisse, and Robert J. Sokol. 2002. "Violence Exposure, Trauma, and IQ and/or Reading Deficits among Urban Children." Archives of Pediatrics and Adolescent Medicine 156:280-85. http://dx.doi.org/10.1001/ archpedi.156.3.280

Ellen, Ingrid Gould and Margery Austin Turner. 1997. "Does Neighborhood Matter? Assessing Recent Evidence." Housing Policy Debate 8:833-66. http://dx.doi.org/10 1080/10511482.1997.9521280

Grogger, Jeff. 1997. "Local Violence and Educational Attainment." Journal of Human Resources 32:659-82. http://dx.doi.org/ $10.2307 / 146425$

Harding, David J. 2003. "Counterfactual Models of Neighborhood Effects: The Effect of Neighborhood Poverty on Dropping Out and Teenage Pregnancy." American Journal of Sociology 109:676-719. http://dx.doi.org/ 10.1086/379217

Harding, David J. 2009. "Collateral Consequences of Violence in Disadvantaged Neighborhoods." Social Forces 88:757-82. http: //dx.doi.org/10.1353/sof .0.0281

Harding, David J. 2010. Living the Drama: Community, Conflict, and Culture among 
Inner-City Boys. Chicago: University of Chicago Press. http://dx.doi.org/10 7208/chicago/9780226316666.001.0001

Hurt, Hallam, Elsa Malmud, Nancy L. Brodsky, and Joan Giannetta. 2001. "Exposure to Violence: Psychological and Academic Correlates in Child Witnesses." Archives of Pediatrics and Adolescent Medicine 155:1351-56. http://dx.doi.org/10.1001/ archpedi.155.12.1351

Kling, Jeffrey R., Jeffrey B. Liebman, and Lawrence F. Katz. 2007. "Experimental Analysis of Neighborhood Effects." Econometrica 75:83-119. http://dx.doi.org/10.1111/j 1468-0262.2007.00733.x

Kling, Jeffrey R., Jens Ludwig, and Lawrence F. Katz. 2005. "Neighborhood Effects on Crime for Female and Male Youth: Evidence from a Randomized Housing Voucher Experiment." Quarterly Journal of Economics 120:87-130. http://dx.doi.org/10.1162/ 0033553053327470

LeDoux, Joseph E. 2000. "Emotion Circuits in the Brain." Annual Review of Neuroscience 23:155-84. http://dx.doi.org/10 1146/annurev.neuro.23.1.155

Levine, Phillip B. and Diane Schanzenbach. 2009. "The Impact of Children's Public Health Insurance Expansion on Educational Outcomes." Forum for Health Economics and Policy 12:1-26. http://dx.doi.org/10.2202/ 1558-9544.1137

Liew, Jeffrey, Erin M. McTigue, Lisa Barrois, and Jan N. Hughes. 2008. "Adaptive and Effortful Control and Academic Self-Efficacy Beliefs on Achievement: A Longitudinal Study of 1st through 3rd Graders." Early Childhood Research Quarterly 23:515-26. http://dx doi.org/10.1016/j.ecresq.2008.07.003

Ludwig, Jens, Brian Jacob, Greg Duncan, James Rosenbaum, and Michael Johnson. 2010. "Neighborhood Effects on Low-Income Families: Evidence from a Housing-Voucher Lottery in Chicago." Working paper, University of Chicago.

Ludwig, Jens, Brian A. Jacob, Michael Johnson, Greg J. Duncan, and James E. Rosenbaum. 2009. "Neighborhood Effects on Low-Income Families: Evidence from a Randomized Hous- ing Voucher Lottery." Working Paper, University of Chicago.

Ludwig, Jens, Helen F. Ladd, and Greg J. Duncan. 2001. "Urban Poverty and Educational Outcomes." Pp. 147-201 in Brookings Wharton Papers on Urban Affairs, edited by William Gale and Janet Rothenberg Pack. Washington, DC: Brookings Institution.

Margolin, Gayla and Elana B. Gordis. 2004. "Children's Exposure to Violence in the Family and Community." Current Directions in Psychological Science 13:152-55. http://dx.doi org/10.1111/j.0963-7214.2004.00296.x

Martinez, Pedro and John E. Richters. 1993. "The NIMH Community Violence Project: II. Children's Distress Symptoms Associated with Violence Exposure." Psychiatry: Interpersonal and Biological Processes 56:22-35.

McEwen, Bruce S. and Robert M. Sapolsky. 1995. "Stress and Cognitive Function." Current Opinion in Neurobiology 5:205-16. http://dx.doi.org/10.1016/ 0959-4388(95) 80028-X

Mendenhall, Ruby, Stefanie DeLuca, and Greg Duncan. 2006. "Neighborhood Resources, Racial Segregation, and Economic Mobility: Results from the Gautreaux Program." Social Science Research 35:892923. http://dx.doi.org/10.1016/j ssresearch.2005.06.007

Osofsky, Joy D. 1999. "The Impact of Violence on Children." Future of Children 9:33-49. http://dx.doi.org/10.2307/1602780

Pribesh, Shana and Douglas B. Downey. 1999. "Why Are Residential and School Moves Associated with Poor School Performance?" Demography 36:521-34. http://dx.doi.org/ 10.2307/2648088

Pynoos, Robert S., Calvin Frederick, Kathi Nader, William Arroyo, Allan Steinberg, Spencer Eth, Francisco Nunez, and Lynn Fairbanks. 1987. "Life Threat and Posttraumatic Stress in School-Age Children." Archives of General Psychiatry 44:1057-63. http://dx.doi.org/10.1001/ archpsyc.1987.01800240031005

Rubinowitz, Leonard S. and James E. Rosenbaum. 2000. Crossing the Class and Color 
Lines: From Public Housing to White Suburbia. Chicago: University of Chicago Press.

Sampson, Robert J., Patrick Sharkey, and Stephen Raudenbush. 2008. "Durable Effects of Concentrated Disadvantage on Verbal Ability among African-American Children." Proceedings of the National Academy of Sciences of the United States of America 105:845-52.http://dx.doi.org/10 1073/pnas.0710189104

Sanbonmatsu, Lisa, Jeffrey Kling, Greg Duncan, and Jeanne Brooks-Gunn. 2006. "Neighborhoods and Academic Achievement: Results from the Moving to Opportunity Experiment." Journal of Human Resources 41:649-91 http: //dx.doi.org/10.3368/jhr.XLI.4.649

Sanbonmatsu, Lisa, Jens Ludwig, Lawrence F. Katz, Lisa A. Gennetian, Greg J. Duncan, Ronald C. Kessler, Emma Adam, Thomas W. McDade, and Stacy Tessler Lindau. 2011. Moving to Opportunity for Fair Housing Demonstration Program - Final Impacts Evaluation. Washington, DC: U.S. Department of Housing and Urban Development.

Scanlon, Edward and Kevin Devine. 2001. "Residential Mobility and Youth Well-Being: Research, Policy, and Practice Issues." Journal of Sociology and Social Welfare 28:119-38.

Shahinfar, Ariana, Janis B. Kupersmidt, and Louis S. Matza. 2001. "The Relation between Exposure to Violence and Social Information Processing among Incarcerated Adolescents." Journal of Abnormal Psychology 110:136-41. http://dx.doi.org/10.1037/ 0021-843X.110.1.136

Sharkey, Patrick. 2010. "The Acute Effect of Local Homicides on Children's Cognitive Performance." Proceedings of the National Academy of Sciences of the United States of America 107:11733-11738. http://dx.doi.org/ 10.1073/pnas.1000690107

Sharkey, Patrick and Felix Elwert. 2011. "The Legacy of Disadvantage: Multigenerational Neighborhood Effects on Cognitive Ability." American Journal of Sociology 116:193481.http://dx.doi.org/10.1086/660009

Sharkey, Patrick, Nicole Strayer, Andrew Papachristos, and Cybele Raver. 2012. "The Effect of Local Violence on Children's Atten- tion and Impulse Control."_American Journal of Public Health 102:2287-93. http://dx doi.org/10.2105/AJPH. 2012.300789

Swanson, Christopher B. and Barbara Schneider. 1999. "Students on the Move: Residential and Educational Mobility in America's Schools." Sociology of Education 72:54-67. http://dx doi.org/10.2307/2673186

Votruba, Mark E. and Jeffrey Kling. 2009. "Effects of Neighborhood Characteristics on the Mortality of Black Male Youth: Evidence from Gautreaux, Chicago." Social Science and Medicine 68:814-23. http://dx.doi.org/ 10.1016/j . socscimed.2008.12.018

Wodtke, Geoffrey, David J. Harding, and Felix Elwert. 2011. "Neighborhood Effects in Temporal Perspective." American Sociological Review 76:713-36. http://dx.doi.org/ 10.1177/0003122411420816

Acknowledgements: We are grateful for funding from the William T. Grant Foundation. Direct correspondence to Patrick Sharkey, Department of Sociology, New York University.

Patrick Sharkey: Department of Sociology, New York University.

E-mail: Patrick.Sharkey@nyu.edu.

Amy Ellen Schwartz: Robert F. Wagner School of Public Service, New York University.

E-mail: Amy.Schwartz@nyu.edu.

Ingrid Gould Ellen: Robert F. Wagner School of Public Service, New York University.

E-mail: Ingrid.Ellen@nyu.edu.

Johanna Lacoe: Price School of Public Policy, University of Southern California.

E-mail: lacoe@price.usc.edu. 